\title{
Papers
}

\section{Informed choice in genetic screening for thalassaemia during pregnancy: audit from a national confidential inquiry}

Bernadette Modell, Rodney Harris, Beverley Lane, Maren Khan, Matthew Darlison, Mary Petrou, John Old, Mark Layton, Lysandros Varnavides

\begin{abstract}
Objective National audit of informed choice in antenatal screening for thalassaemia.

Design Audit from the UK Confidential Enquiry into Counselling for Genetic Disorders.

Setting Thalassaemia module of the UK Confidential Enquiry into Counselling for Genetic Disorders.

Subjects 138 of 156 couples who had had a pregnancy affected by a major $\beta$ thalassaemia from 1990 to 1994.
\end{abstract}

Main outcome measures How and when genetic risk was identified for each couple, and whether and when prenatal diagnosis was offered.

Results Risk was detected by screening before or during the first pregnancy in $49 \%(68 / 138)$ of couples and by diagnosis of an affected child in $28 \%(38 / 138)$ of couples. Prenatal diagnosis was offered in $69 \%$ (274/400) of pregnancies, ranging from $94 \%$ (122/130) for British Cypriots to 54\% (80/149) for British Pakistanis and from $90 \%$ in the south east of England to 39\% in the West Midlands. Uptake of prenatal diagnosis was $80 \%(216 / 274)$, ranging from $98 \%(117 / 120)$ among British Cypriots in either the first or second trimester to $73 \%$ (35/48) among British Pakistanis in the first trimester and 39\% $(11 / 28)$ in the second trimester. A demonstrable service failure occurred in 28\% (110/400) of pregnancies, including 110 of 126 where prenatal diagnosis was not offered and 48 of 93 that ended with an affected liveborn infant.

Conclusion Although antenatal screening and counselling for haemoglobin disorders are standard practices in the United Kingdom, they are delivered inadequately and inequitably. An explicit national policy is needed, aiming to make prenatal diagnosis in the first trimester available to all couples and including ongoing national audit.

\section{Introduction}

The UK National Confidential Enquiry into Counselling for Genetic Disorders aims to evaluate the quality of genetic counselling provided within general health services. ${ }^{12}$ Thalassaemia was selected as a pilot to audit population screening for recessively inherited disor- ders $^{3}$ because antenatal screening for haemoglobin disorders is standard practice in the United Kingdom ${ }^{4}$ and cases could be identified through national registers. ${ }^{5}{ }^{6}$ The objective of carrier screening is to permit couples who are at risk an informed choice among available options, including prenatal diagnosis in every pregnancy. ${ }^{7}$ The inquiry therefore focused on evaluating parents' access to information and choice.

When performed as recommended ${ }^{8}$ the "haemoglobinopathy screen" is an almost ideal screening test. It combines measurement of the red cell indices (to detect microcytosis typical of thalassaemias) and electrophoresis for abnormal haemoglobins. Sensitivity is $100 \%$ for common abnormal haemoglobins and over $96 \%$ for thalassaemias, and specificity is $100 \%$ for both. When a clear policy and multidisciplinary cooperation are in place it is possible to identify practically all couples at risk in their first pregnancy, but with present antenatal booking practice this is rarely achieved before the second trimester. ${ }^{9}$ Prenatal diagnosis in the first trimester, which has been feasible in all cases since $1990,{ }^{10}$ should be offered in all subsequent pregnancies provided that the woman presents in time.

With an appropriate service, utilisation of prenatal diagnosis (percentage of pregnancies at risk in which a prenatal diagnosis is actually performed) should approximate uptake (percentage of couples requesting prenatal diagnosis when it is offered). Although uptake of prenatal diagnosis for thalassaemia is over $80 \%$ in south east England, ${ }^{11}$ national audits conducted in 1985 and 1997 showed 50\% utilisation and wide variations by region and ethnic group. ${ }^{125}$ In addition, a pilot confidential inquiry indicated that $60 \%$ of couples with a thalassaemic child born between 1980 and 1990 had not been informed of their risk during pregnancy. ${ }^{13}$ The Confidential Enquiry into Counselling for Genetic Disorders therefore undertook a formal study of the proportion of couples at risk who received timely risk detection and counselling during pregnancy.

The inquiry requested permission to review the clinical records of couples who had had a pregnancy affected by a major beta thalassaemia in the five year period from 1990 to 1994, identified through national registers. ${ }^{56}$ These couples provide a representative

\author{
St Mary's Hospital, \\ Manchester \\ M13 0JH \\ Rodney Harris \\ professor of medical \\ genetics \\ Beverley Lane \\ research nurse for \\ Confidential Enquiry \\ into Counselling for \\ Genetic Disorders \\ Royal Free and \\ University College \\ London Medical \\ School, Department \\ of Primary Care \\ and Population \\ Sciences, \\ Whittington \\ Hospital, London \\ N19 5NF \\ Bernadette Modell \\ professor of \\ community genetics \\ Maren Khan \\ research midwife \\ Roval Free and \\ University College \\ London Medical \\ School, Centre for \\ Health Informatics \\ and \\ Multiprofessional \\ Education, \\ Whittington \\ Hospital \\ Matthew Darlison \\ research fellow \\ Royal Free and \\ University College \\ London Medical \\ School, Department \\ of Obstetrics and \\ Gynaecology, \\ London \\ WC1E 6HX \\ Mary Petrou \\ clinical molecular \\ geneticist \\ continued over
}

BMJ 2000;320:337-41 
King's College Hospital Medical School, Department of Haematological Medicine, King's College Hospital, London SE5 9RS

Mark Layton senior lecturer Lysandros

Varnavides clinical molecular geneticist

Institute of Molecular Medicine, John Radcliffe Hospital, Headington, John Old clinical molecular geneticist

Correspondence to: B Modell b.modell@ucl. acuk Oxford OX3 9DU

sample of the population at risk for haemoglobin disorders, as follows. Nationally every year there are at least 75000 infants born to women in ethnic groups at risk of haemoglobin disorders $(11 \% \text { of the total })^{14}{ }^{15}$ : an essentially random 7120 of these women carry a haemoglobin disorder as do about 870 of their partners. A random $25 \%$ of these pregnancies at risk (about 218 a year) are affected and end either in an affected liveborn infant or in a termination of pregnancy after prenatal diagnosis. About 20\% of these have a major thalassaemia, and these can be almost completely ascertained through national registers. The method of case finding leads to overrepresentation of affected pregnancies among study couples (50\% instead of $25 \%$ ), but couples are unselected in terms of antenatal care provided, which is the subject of inquiry. The service these couples receive is therefore representative of that provided nationally.

\section{Methods}

\section{The thalassaemia module}

The thalassaemia module of the UK Confidential Enquiry into Counselling for Genetic Disorders was initiated in 1997. Cases for the module were found through the UK register of prenatal diagnosis for haemoglobin disorders and the UK thalassaemia (patient) register, which are both over $95 \%$ complete. ${ }^{56}$ Because of the lag time in diagnosing and registering patients the patient register was then up to date to 1995 , so the inquiry focused on pregnancies affected by a major $\beta$ thalassaemia in the five years from 1990 to 1994 . The team identified 172 affected pregnancies in 156 women. A wide range of records was made available, but the formal protocol required review of obstetric notes. In 34 cases the responsible obstetrician could not be identified, did not respond, or could not locate the notes, so the inquiry reported on 137 pregnancies in 124 women ( $80 \%$ of those identified).

\section{Audit}

To audit the service provided to couples we examined all available records and obtained the full obstetric history of 138 of the 156 women identified (86\%). Multiple information sources were used for most cases. Primary sources were: obstetric notes (91 women), notes from specialist prenatal diagnosis centres (33), a national register for prenatal diagnosis (10), general practitioners' notes (3), and correspondence (1). Information on whether and how risk was recognised was available for all cases through pathology reports, notes

Table 1 At risk pregnancies, risk recognition, and ethnic group. Values are numbers (percentages) of couples

\begin{tabular}{lccccc} 
& \multicolumn{2}{c}{ First pregnancy } & & \multicolumn{2}{c}{ All pregnancies } \\
\cline { 2 - 3 } \cline { 6 - 6 } Ethnic group & Total No & $\begin{array}{c}\text { No (\%) offered } \\
\text { prenatal diagnosis }\end{array}$ & & Total No & $\begin{array}{c}\text { No (\%) offered } \\
\text { prenatal diagnosis }\end{array}$ \\
\hline Cypriot $^{\star}$ & 42 & $34(81)$ & & 130 & $119(92)$ \\
\hline Indian & 26 & $13(50)$ & & 73 & $46(63)$ \\
\hline Other† & 10 & $4(40)$ & & 28 & $17(61)$ \\
\hline Pakistani* & 52 & $15(29)$ & & 149 & $76(51)$ \\
\hline Bangladeshi & 8 & $2(25)$ & & 20 & $7(35)$ \\
\hline Total & 138 & $68(49)$ & & 400 & $268(67)$
\end{tabular}

${ }^{*}$ Difference between proportion of Cypriot and Pakistani couples whose risk was detected in first pregnancy is highly significant, $\chi^{2}=62.9, \mathrm{P}<0.0001$ ).

fltalian or other Mediterranean, Chinese or other South East Asian, African-Caribbean, Middle Eastern.

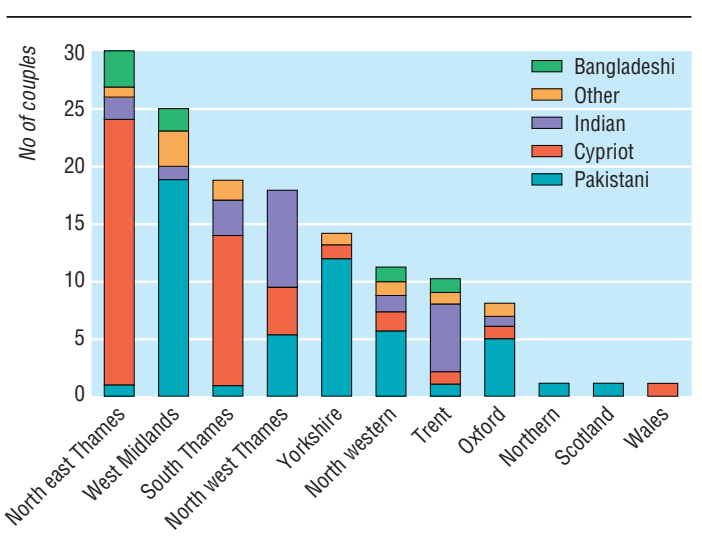

Fig 1 Distribution and ethnic group of 138 study couples by 1991 regional health authority or country. Other=Italian or other Mediterranean, Chinese or other South East Asian, African-Caribbean, and Middle Eastern

about a previous affected child or previous recognition of risk, records of couples' choices, and correspondence. Records of information and counselling varied from none to detailed correspondence among general practitioners, haematologists, obstetricians, and counsellors.

For each couple we extracted data on ethnic group, region of residence, and how and when risk was detected. For each viable pregnancy with antenatal care in the United Kingdom we extracted data on offer and uptake of prenatal diagnosis and outcome.

\section{Results}

The 138 women had had 485 pregnancies. Eighty five pregnancies were ineligible (38 miscarriages, 12 social abortions, 3 ectopics, 2 hydatidiform moles, 6 with another partner, 10 live births abroad, and 14 before 1980 when prenatal diagnosis became established), leaving 400 study pregnancies. Figure 1 shows the regional and ethnic distribution of the couples.

\section{Risk recognition and offer of prenatal diagnosis}

Events in the first pregnancy are the best indicator of screening practice as risk should normally be recognised at this stage. Table 1 and figure 2 show that only $49 \%$ of couples were informed and offered prenatal diagnosis in their first pregnancy. By the third pregnancy the proportion had risen to over $80 \%$, but the main reason for the increase was that 38 couples ( $28 \%$ of those at risk) were identified through the diagnosis of an affected child. Risk was recognised in 43\% of first pregnancies occurring before 1990 (27 of 63) and in $55 \%$ since 1990 (41 of 74). Figure 2 shows that most couples whose risk was recognised in the first pregnancy had an informed choice in every pregnancy, whereas many of those "missed" in the first pregnancy were missed again, indicating systematic differences in service provision.

Overall, risk was recognised before 24 weeks' gestation in 271 of 400 pregnancies. There was evidence of service failure in 100 of the remaining 129 pregnancies (table 2 ).

Risk was recognised later than 24 weeks' gestation in 23 pregnancies. This was not owing to late presenta- 
tion as 10 available referral letters from doctors showed that six women presented in the first trimester and four in the second. Two had a late prenatal diagnosis, one affected pregnancy was terminated at 27 weeks, and 10 liveborn infants were affected.

Ethnic variations-The proportion of pregnancies where prenatal diagnosis was offered ranged from $81 \%$ of first pregnancies and 92\% of all pregnancies in British Cypriots, to $29 \%$ of first pregnancies and $51 \%$ of all pregnancies in British Pakistanis.

Prenatal diagnosis in the first trimester, feasible in all cases since 1990, was offered to $87 \%$ of British Cypriots and $50 \%$ of British Pakistanis with eligible pregnancies and to 62\% (8 of 13) of British Cypriot couples and 9\% (3 of 32) of British Pakistani couples with eligible first pregnancies.

Regional variations - In south east England prenatal diagnosis was offered in 79\% (25 of 30) of first pregnancies and 92\% (83 of 90) of all pregnancies. In the West Midlands and Anglia and Oxford prenatal diagnosis was offered in 20\% of first pregnancies ( 5 of 25 and 1 of 8 respectively) and 39\% of all pregnancies (23 of 59 and 9 of 23 respectively).

Uptake of prenatal diagnosis when offered was $80 \%$ (214 of 266) but varied with ethnic origin and gestation (fig 3). For example, uptake by British Pakistanis was $73 \%$ (35 of 48) in the first trimester, with 11 of 12 affected pregnancies being terminated, and 39\% (11 of 28 ) in the second trimester, with four of seven affected pregnancies being terminated.

Couples' uptake of prenatal diagnosis was not always consistent. Nine of 10 couples who declined and had an affected child requested prenatal diagnosis in subsequent pregnancies. Seven who declined and had an unaffected child declined again. Six couples who had had a prenatal diagnosis, later declined: one couple after an intrauterine death associated with the procedure, three after a mid-trimester abortion, one after a first trimester abortion, and one after continuing a known affected pregnancy and having a mildly affected child.

Affected liveborn infants-Overall, 93 of the 201 affected pregnancies ended in a liveborn infant (fig 4). This could not be foreseen in six cases (atypical carrier, partner abroad) and followed parental choice in 37 (33 declined prenatal diagnosis, 4 continued an affected pregnancy). Service failure occurred in $48(52 \%)$ cases (risk not detected, detected after 24 weeks' gestation, lost, or couple not counselled). Circumstances were unclear in one case. More than two thirds of affected liveborn infants were to British Pakistani or Bangladeshi parents, and more than two thirds occurred in the midlands and the north.

\section{Discussion}

Screening and counselling for genetic disorders In the United Kingdom haemoglobin disorders are two thirds as common as cystic fibrosis, ${ }^{14} 15$ and antenatal carrier screening is standard practice. ${ }^{4}$ Eighty per cent of couples at risk of a serious haemoglobin disorder are at risk of a sickle cell disorder. Detailed study of the screening process is feasible for the $20 \%$ subset at risk of thalassaemia, because national registers exist. The UK Confidential Enquiry into Counselling for Genetic Disorders therefore con-

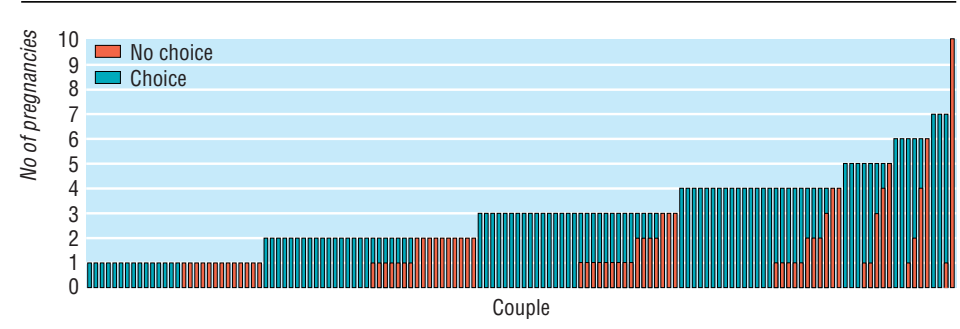

Fig 2 Availability of information and choice to 138 couples at risk of a thalassaemic pregnancy, from national inquiry into genetic counselling, ranked in order of total number of pregnancies. Each column represents one woman, and shows all viable pregnancies at risk since 1980 with antenatal care in the United Kingdom

Table 2 Reasons for failure to offer prenatal diagnosis in 126 pregnancies

\begin{tabular}{|c|c|c|}
\hline Reason & $\begin{array}{l}\text { No }(\%) \text { of } \\
\text { couples }\end{array}$ & Notes \\
\hline Unavoidable & $10(8)$ & $\begin{array}{l}3 \text { atypical indices, } 3 \text { partners unavailable, } 2 \text { late } \\
\text { presentations of pregnancy, } 2 \text { wrong dates }\end{array}$ \\
\hline Woman not screened & $35(28)$ & No $\mathrm{Hb} \mathrm{A}_{2}$ estimation or electrophoresis \\
\hline Partner not tested & $29(23)$ & No indices, $\mathrm{Hb} \mathrm{A}_{2}$ estimation, or electrophoresis for partner \\
\hline Laboratory error & $15(12)$ & $\begin{array}{l}1 \text { inappropriate test, } 3 \text { false low } \mathrm{Hb}_{2}, 3 \text { borderline indices, } \\
3 \text { clerical or communication errors, } 3 \text { false risk assessments, } \\
2 \text { "knock on" errors* }\end{array}$ \\
\hline Undue delay in screening & $13(10)$ & Late detection of risk \\
\hline Failed communication & $5(4)$ & $\begin{array}{l}4 \text { general practitioner reported risk when referring, no action } \\
1 \text { carrier father given "non-carrier" card }\end{array}$ \\
\hline Manifest risk not recognised & $5(4)$ & $\begin{array}{l}\text { Previous history (existing affected child or known risk) } \\
\text { noted, no action }\end{array}$ \\
\hline Not counselled & $4(3)$ & Carrier state detected in both partners, no action \\
\hline Risk "lost" & $4(3)$ & $\begin{array}{l}\text { No record in obstetric notes or laboratory of a risk already } \\
\text { detected in a previous pregnancy }\end{array}$ \\
\hline Unknown & $6(5)$ & \\
\hline Total & $126(100)$ & \\
\hline
\end{tabular}

*Failure to recognise risk or retest during a pregnancy because of false negative result in earlier pregnancy.

ducted a national audit of informed choice for risk of thalassaemia from 1990 to 1994 . The offer of prenatal diagnosis, which is a precondition for choice, was the principal indicator. Only half the couples at risk received a service that allowed them an informed choice in every pregnancy, ranging from $86 \%$ of British Cypriots to 33\% of British Pakistanis and from $83 \%$ of residents in the south east to $16 \%$ of of those in

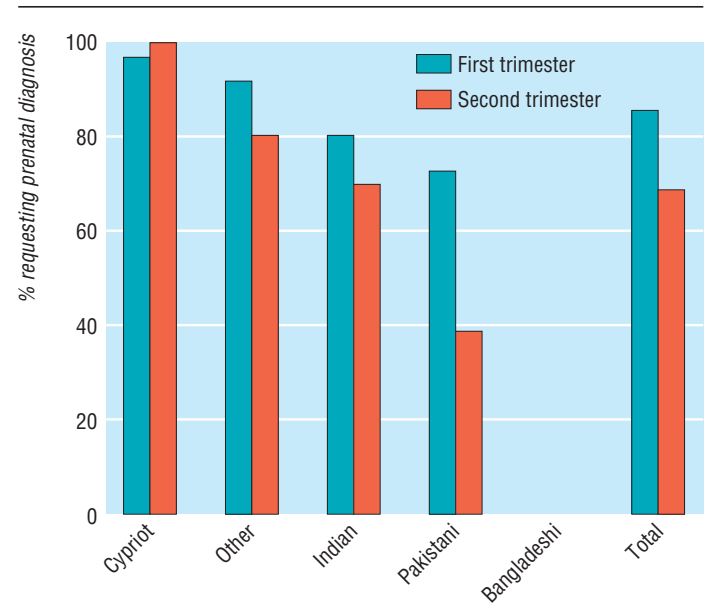

Fig 3 Uptake of prenatal diagnosis by ethnic group and gestation at counselling. Fisher's exact test for British Pakistanis showed a significant difference $(P=0.004)$ in proportion requesting prenatal diagnosis in first versus second trimester 


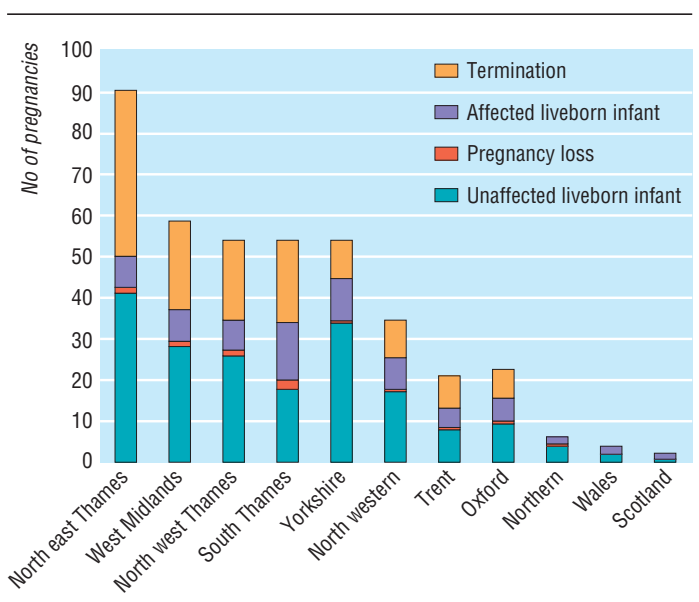

Fig 4 Outcome of 403 conceptions at risk (400 pregnancies) by region. Regional differences are highly significant $\left(\chi^{2}\right.$ test on 8 $\mathrm{df}=96.87, \mathrm{P}<0.001)$

the West Midlands. Almost one third of couples (mostly British Pakistanis) first discovered their risk through the diagnosis of an affected child, and over half of all affected liveborn infants were associated with a service failure. There was little change in service quality between 1980 and 1995, and there is limited evidence of subsequent change.

\section{Role of inadequate or absent screening policies}

The wide range of problems identified by the inquiry underlines the multidisciplinary nature of antenatal genetic screening and shows the need for explicit policies, good communication, and a clear line of responsibility. Clustering of problems in some regions identifies inadequate local screening policies as the principal reason for uneven service delivery. Many districts, predominantly in south east England, developed an explicit policy in the early 1980s when prenatal diagnosis became available, and they provide a consistent high quality service. Recruitment of other districts has been

\section{What is already known on this topic}

The aim of antenatal screening for haemoglobin disorders is to allow couples at risk an informed choice, including the option of prenatal diagnosis, in every pregnancy

The observed utilisation of prenatal diagnosis is lower than predicted, and the extent to which this reflects couples' informed choices versus problems in service delivery was unclear

\section{What this paper adds}

The UK confidential inquiry into antenatal screening for thalassaemia has shown that: only half of all couples at risk obtain full access to information and choice; over half of all affected liveborn infants are associated with a demonstrable service failure; the service is not provided to many British Pakistanis and Bangladeshis because of ethnic stereoptyping; and prenatal diagnosis is highly acceptable to all ethnic groups at risk, especially when offered in the first trimester

A national policy on screening for haemoglobin disorders is needed, as the main cause of service failures is inadequate policy development at the district level slow despite the increasing numbers and changing regional distribution of ethnic groups at risk. ${ }^{6}{ }^{14}{ }^{15}$ In a 1999 postal survey of clinical directors and heads of midwifery, 104 units $(65 \%)$ were reported to have neither local nor regional written policies for screening for haemoglobin disorders (unpublished data). The problems identified must also apply for sickle cell disorders because the same screening and counselling approach applies for all haemoglobin disorders.

\section{Importance of early detection of risk, and counselling}

The choices of British Pakistanis highlight the importance of the timing of offering prenatal diagnosis. In this group, uptake of prenatal diagnosis in the first trimester is over $70 \%$ and over $90 \%$ of affected pregnancies are terminated, whereas uptake of diagnosis in the second trimester is $40 \%$ and half of the affected pregnancies are terminated. The same preference applies for couples of any ethnic origin but is often masked by higher acceptance of late abortion. Informed choice clearly requires the offer of diagnosis in the first trimester whenever possible, which will require increased involvement of primary care teams. ${ }^{16}$ With truly informed choice there would be $75 \%-80 \%$ national utilisation of prenatal diagnosis for thalassaemia.

\section{Role of ethnic stereotyping}

Equity in medical services requires facilities for crossing social, educational, language, and cultural barriers. British Cypriots are highly aware of thalassaemia and have high expectations; many "beat the system" by asking their doctor for prepregnancy screening and so obtain prenatal diagnosis in the first trimester of their first pregnancy. By contrast, most British Pakistanis depend on health workers for information and screening and few know that prenatal diagnosis in the first trimester is available with religious agreement in Pakistan and Iran. ${ }^{17}$ We show here that British Pakistanis' low utilisation of prenatal diagnosis reflects inadequate risk detection, lack of awareness, poor communication, and a strong preference for early testing. It is, however, often taken to support a view (documented in several notes) that Muslims "do not want" prenatal diagnosis. This leads to half hearted screening and self confirming results, so the population that needs the best service obtains the worst.

The eight British Bangladeshi couples studied encountered most problems. There was no evidence of any counselling for four couples, no couple was counselled in their mother tongue, and two couples at risk of haemoglobin $\mathrm{E} / \beta$ thalassaemia were not offered prenatal diagnosis because their risk was incorrectly assessed. ${ }^{3}$ Although two haemoglobinopathy counsellors with appropriate language skills are in post in the United Kingdom, they are geographically inaccessible to most British Bangladeshis. ${ }^{18}$ A distance interpreting or counselling service could help to overcome such problems. ${ }^{19}$

\section{Conclusion}

The UK Confidential Enquiry into Counselling for Genetic Disorders shows the need for a national policy on screening for haemoglobin disorders, aiming to offer prenatal diagnosis in the first trimester in all pregnancies at risk, and including ongoing audit. To 
maintain the audit initiated by the inquiry the UK thalassaemia register now collects information about the circumstances of each new affected birth.

We thank Paula Williamson and Mark Griffin for statistical advice.

Contributors: BM provided data from the UK thalassaemia register, participated in planning data collection and analysis, checked and analysed all data, and drafted the paper. $\mathrm{RH}$ conceived and implemented the concept of the genetic confidential inquiry, obtained financial support, supervised and coordinated all modules, participated in planning data analysis, and edited the paper. BL participated in planning data collection and analysis, conducted the inquiry, collected and entered the data, participated in planning data analysis, coordinated the study, and edited the paper. MK ensured that data from the UK thalassaemia register was complete, helped identify responsible obstetricians, and assisted in checking data. MD contributed to the principles of data analysis and edited the paper. ML provided data from the UK register of prenatal diagnosis for haemoglobin disorders and some patient records, and participated in planning data analysis. MP and JO provided data from the UK register of prenatal diagnosis for haemoglobin disorders, checked patient records, and participated in planning data analysis. LV provided data from the UK register of prenatal diagnosis for haemoglobin disorders and checked patient records. RH and BM will act as guarantors for the paper.

Funding: The UK Confidential Enquiry into Counselling for Genetic Disorders was sponsored by the Royal College of Physicians and supported by the UK Department of Health. BM is supported by the Wellcome Trust as a prinical research fellow.

Competing interests: None declared.

1 Harris R. How well do we manage families with genetic problems? national confidential enquiry into counselling for genetic disorders should tell us. BMJ 1991;303:1412-3.

2 Harris R, Lane B, Harris HJ, Williamson P, Dodge J, Modell B, et al. National confidential enquiry into counselling for genetic disorders by non-geneticists: general recommendations and specific standards for improving care. Brit J Obst Gynaecol 1999;106:658-63.

3 National confidential enquiry into counselling for genetic disorders Homozygous beta thalassaemias, Great Britain 1990-94. Report to the Department of Health from the steering committee, 1998.
4 Sickle cell, thalassaemia and other haemoglobinopathies. Report of a working party of the Standing Medical Advisory Committee. London: HMSO, 1994.

5 Modell B, Petrou M, Layton M, Varnavides L, Slater C, Ward RHT, et al. Audit of prenatal diagnosis for haemoglobin disorders in the United Kingdom: the first 20 years. BMJ 1997;315:779-84.

6 Modell B, Khan M, Darlison M. Survival in beta thalassaemia major in the United Kingdom: data from the UK thalassaemia register. Lancet 2000 (in press).

7 Nuffield Council on Bioethics. Genetic screening, ethical issues. London: Nuffield Council on Bioethics.

8 Working party of the General Haematology Task Force of the British Committee for Standards in Haematology. Guideline. The laboratory diagnosis of haemoglobinopathies. Brit J Haematol 1998;101:783-92.

9 Neuenschwander $\mathrm{H}$, Modell $\mathrm{B}$. The process of antenatal sickle cell screening at a north London hospital. BMJ 1997;315:784-5.

10 Old JM, Varawalla NY, Weatherall DJ. Rapid detection and prenatal diagnosis of beta-thalassaemia: studies in Indian and Cypriot populations in the UK. Lancet 1990;336:834-7.

11 Modell B, Ward RHT, Fairweather DVI. Effect of introducing antenata diagnosis on the reproductive behaviour of families at risk for thalassaemia major. BMJ 1980;2:737-40.

12 Modell B, Petrou M, Ward RHT, Fairweather DVI, Rodeck C, Varnavide LA, et al. Effect of fetal diagnostic testing on the birth-rate of thalassaemia in Britain. Lancet 1985;2:1383-6.

13 Modell B. EC concerted action on developing patient registers as a tool for improving service delivery for haemoglobin disorders. In: Fracchia GN, Theophilatou M, eds. Health services research. Amsterdam: IOS Press, 1993.

14 Health Education Authority. Sickle cell and thalassaemia: achieving health gain. Guidance for commissioners and providers. London: HEA, 1998.

15 Hickman M, Modell B, Greengross P, Chapman C, Layton M, Gill M, et al Mapping the prevalence of sickle cell and $\beta$ thalassaemia in England: recommended rates for local service planning. Brit J Haematol 1999;104: 860-7.

16 Modell M, Wonke B, Anionwu E, Khan M, See Tai S, Lloyd M, et al. A multidisciplinary approach for improving services in primary care: the example of screening for haemoglobin disorders. BMJ 1998;7161: $788-91$.

17 Anionwu EN. Ethnic origin of sickle and thalassaemia counsellors; does it matter? In: Kelleher D, Hillier D, eds. Research in cultural differences in health. Routledge: London, 1996.

18 Petrou M, Modell B. Prenatal screening for haemoglobin disorders. Prenat Diag 1995;15:1275-95.

19 Jones D, Gill P. Breaking down language barriers: the provision of accessible interpreting services for all. BMJ 1998;316:1476.

(Accepted 29 November 1999)

\title{
Quality of life related to fear of falling and hip fracture in older women: a time trade off study
}

\author{
G Salkeld, I D Cameron, R G Cumming, S Easter, J Seymour, S E Kurrle, S Quine
}

\begin{abstract}
Objective To estimate the utility (preference for health) associated with hip fracture and fear of falling among older women.

Design Quality of life survey with the time trade off technique. The technique derives an estimate of preference for health states by finding the point at which respondents show no preference between a longer but lower quality of life and a shorter time in full health.

Setting A randomised trial of external hip protectors for older women at risk of hip fracture.

Participants 194 women aged $\geqslant 75$ years enrolled in the randomised controlled trial or who were eligible for the trial but refused completed a quality of life interview face to face.

Outcome measures Respondents were asked to rate their own health by using the Euroqol instrument and then rate three health states (fear of falling, a "good" hip fracture, and a "bad" hip fracture) by using time trade off technique.
\end{abstract}

Results On an interval scale between 0 (death) and 1 (full health), a "bad" hip fracture (which results in admission to a nursing home) was valued at 0.05 ; a "good" hip fracture (maintaining independent living in the community) 0.31 , and fear of falling 0.67 . Of women surveyed, $80 \%$ would rather be dead (utility $=0$ ) than experience the loss of independence and quality of life that results from a bad hip fracture and subsequent admission to a nursing home. The differences in mean utility weights between the trial groups and the refusers were not significant. A test-retest study on 36 women found that the results were reliable with correlation coefficients within classes ranging from 0.61 to 0.88 .

Conclusions Among older women who have exceeded average life expectancy, quality of life is profoundly threatened by falls and hip fractures. Older women place a very high marginal value on their health. Any loss of ability to live independently in the community has a considerable detrimental effect on their quality of life.
Social and Public Health Economics Research Group (SPHERe),

Department of Public Health and Community Medicine, University of Sydney, New South Wales 2006,

Australia

G Salkeld

senior lecturer

continued over

BMJ 2000;320:241-6 